Argonne Rational Laboratory

A NOTE ON ERROR ESTIMATION WHEN A CALIBRATION CURVE IS USED by

Arthur H. Jaffey and Jerome L. Lerner

DISTRIBUTION OF THE DOCUMENT IS UNLIMITED 


\section{DISCLAIMER}

This report was prepared as an account of work sponsored by an agency of the United States Government. Neither the United States Government nor any agency Thereof, nor any of their employees, makes any warranty, express or implied, or assumes any legal liability or responsibility for the accuracy, completeness, or usefulness of any information, apparatus, product, or process disclosed, or represents that its use would not infringe privately owned rights. Reference herein to any specific commercial product, process, or service by trade name, trademark, manufacturer, or otherwise does not necessarily constitute or imply its endorsement, recommendation, or favoring by the United States Government or any agency thereof. The views and opinions of authors expressed herein do not necessarily state or reflect those of the United States Government or any agency thereof. 


\section{DISCLAIMER}

Portions of this document may be illegible in electronic image products. Images are produced from the best available original document. 
The facilities of Argonne National Laboratory are owned by the United States Government. Under the terms of a contract (W-31-109-Eng-38) between the U. S. Atomic Energy Commission, Argonne Universities Association and The University of Chicago, the University employs the staff and operates the Laboratory in accordance with policies and programs formulated, approved and reviewed by the Association.

\section{MEMBERS OF ARGONNE UNIVERSITIES ASSOCIATION}

The University of Arizona Carnegie-Mellon University Case Western Reserve University The University of Chicago University of Cincinnati Illinois Institute of Technology University of Illinois Indiana Univorsity Iowa State University The Iniversity of Iowa
Kansas State University The University of Kansas Loyola University Marquette University Michigan State University The University of Michigan University of Minnesota Universily of Missuuri Nerthwestern IInixersity Univeroity of Notre Dame
The Ohio State University Ohio University The Pennsylvania State University Purdue University Saint Louis University Southern Tllinois University University of Texas Washington University Wayne Stato Univer aity The Universily of Wisconsin

\section{LEGAL NOTICE}

This report was prepared as an account of Government sponsored work. Neither the United States, nor the Commission, nor any person acting on behalf of the Commission:

A. Makes any warranty or representation, expressed or implied, with respect to the accuracy, completeness, or usefulness of the information contained in thio report, or that the use of dny infurmalion, apparatus, method, or process disclosed in this report may not infringe privately owned rights; or

B. Assumes any liabilities with respect to the use of, or for damages resulting from the use of any information, apparatus, method, or process disclosed in this report.

As used in the above, "person acting on behalf of the Commission" includes any employee or contractor of the Commission, or employee of such contractor, to the extent that such employee or contractor of the Commission, or employee of such contractor prepares, disseminates, or provides access to, any information pursuant to his employment or contract with the Commission, or his employment with such contractor.

Printed in the United States of America Available from

Clearinghouse for Federal Scientific and Technical Information National Bureau of Standards, U. S. Department of Commerce Springfield, Virginia 22151

Price: Printed Copy $\$ 3.00 ;$ Microfiche $\$ 0.65$ 
ARGONNE NATIONAL LABORATORY

9700 South Cass Avenue

Argonne, Illinois 60439

\section{A NOTE ON ERROR ESTIMATION WHEN A CALIBRATION CURVE IS USED}

by

Arthur H. Jaffey and Jerome L. Lerner

Chemistry Division

B. Assumes any linbiltules wht respect to the uae of, or for damages resulung from the

As used in tho a apparatus, method, or process disclosed in tals report. - As used in the above. "person actung on behalf of the Commission" incides

ployec or contractor of the commission, or employee of such contractor, to tho any emdissemingloyee or contractor of tho Commission, or employec of such contractor prepares.

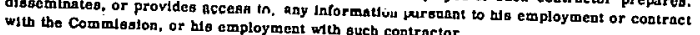

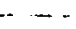

July 1969 
$\therefore \quad \because \cdots$

MS THISPAGE WAS INTENTIONALLY LEFT BLANK 


\title{
A NOTE ON ERROR ESTIMATION WHEN A CALIBRATION CURVE IS USED
}

\author{
by
}

Arthur H. Jaffey and Jerome L. Lerner

\begin{abstract}
This note examines error estimation associated with a particular use of a calibration curve. The essential features appear in the case of a measuring device whose detection efficiency $Y$ varies with time $x$. Measurements with several standard samples are used to construct a calibration curve of efficiency versus time, $Y=f(x)$, and this curve is used to correct all measurements to a standard efficiency: The measured values for one of the standards are also so corrected, and the squared error in the average is estimated as a sum of squared deviations from the average, divided by $\forall$, the number of degrees of freedom. With $\mathrm{n}$ denoting the number of data points with the specified standard, $\nu$ should be less than $n$, as in the usual least-squares analysis, because of the correlation introducted by use of the same quantities in estimating $\mathrm{Y}=\mathrm{f}(\mathrm{x})$. It is conjectured that $\psi$ should be taken as $n-1-F \theta$, where $F$ is the number of fitted parameters used in $\mathrm{Y}=\mathrm{f}(\mathrm{x})$ in addition to the location parameter, and $\theta=\mathrm{n} / \mathrm{p}$, with $\mathrm{p}$ the total number of points used in estimating $Y=f(x)$. The conjecture is not proven, but agrees closely with results evaluated for some sample calibration curves. These results are determined analytically for a straight line $\mathrm{Y}=\mathrm{f}(\mathrm{x})$, and through Monte Carlo sampling for a 4th- and an 8th-order polynomial curve. The appendix includes somediscussion on the choice of an adequate pseudorandom generator of Gaussian deviates.
\end{abstract}

We consider a calibration curve $Y=f(x)$, which is to be used to correct a measurement $y_{i}$ at $x_{i}$ to a standard condition through the relation $y_{i} / Y_{i}=y_{i} / f\left(x_{i}\right)$. Here $x_{i}$ may represent a quantity like counting rate, concentration, pressure, or time, and $\mathrm{y}_{i} / \mathrm{Y}_{i}$ is the measurement reduced to a standard counting efficiency; concentration, pressure, or time. The "true" calibration curve $Y=f(x)$ is unknown, but is estimated as $\hat{\hat{Y}}_{i}=\hat{\mathrm{f}}\left(\mathrm{x}_{\mathrm{i}}\right)$ from error-containing $\mathrm{y}_{i}$-values measured at various $\mathrm{x}_{i}{ }^{\prime} \mathrm{s}$. 
When a new $\mathrm{y}_{\mathrm{h}}$ is measured, the value corrected from the estimated calibration curve is then $z_{h}=y_{h} / \hat{Y}_{h}=y_{h} / \hat{f}\left(x_{h}\right)$. The estimated calibration factor $\hat{\mathrm{Y}}_{\mathrm{h}}$ is not the "true" value $\mathrm{Y}_{\mathrm{h}}$, but deviates from it due to the error in estimating the curve. The actual error in $z_{h}$ is then a combination of the measurement error in $y_{h}$ and the error in $\hat{Y}_{h}$, i:e.; $\sigma\left(z_{h}\right)$ is a combination of $\sigma\left(y_{h}\right)$ and $\sigma\left(\hat{Y}_{h}\right)$. For another measurement $y_{j}\left(a t x_{j}\right)$ the error in $\mathbf{z}_{j}=y_{j} / \hat{Y}_{j}$, i.e., $\sigma\left(z_{j}\right)$, is also a combination of $\sigma\left(y_{j}\right)$ and $\sigma\left(\hat{Y}_{j}\right)$. Though yh and $y_{j}$ are independent measurements, $\hat{Y}_{h}$ and $\hat{Y}_{j}$, being derived from the same estimated curve, are subject to the same source of error. Hence, $z_{h}$ and $z_{j}$ are correlated.

This correlation is potentially of interest only when the results $z_{h}$ and $z_{j}$ are combined in some function $w=g\left(z_{h}, z_{j}\right)$. If we calculate $\sigma(w)$ from $\sigma\left(z_{h}\right)$ and $\sigma\left(z_{j}\right)$, we should include the effect of the correlation between $z_{h}$ and $z_{j}$. This correlation can be marked when a number of $z_{i}$-values are so combined, as when an average is formed:

$$
\bar{z}=\frac{1}{n} \sum_{i=1}^{n} z_{i} .
$$

It is well-known that such correlation effects do not cause a systematic shift in an estimated $\bar{z}$, but they may have a marked effect upon the estimate of $\sigma(\bar{z})$, the error in $\bar{z}$, when the calibration error is comparable to the measurement error.

We shall not discuss this simple case any further. $\sigma(\bar{z})$ may be calculated from values of $\sigma\left(z_{i}\right), \sigma\left(\hat{Y}_{i}\right)$, and $\operatorname{cov}\left(z_{i}, z_{j}\right)$ (or their estimates) for $i, j=1,2, \ldots, n$.

We examine a more complex case in which some of the $y_{i}$-values used in constructing the calibration curve are also calculated as $z_{i}{ }^{\prime}{ }_{0}^{*}$ Such a situation may arise when several different standards are used in constructing the calibration curve, and the averaged value of the curvecorrected measurements from one standard is desired. These results will have some scatter arising from measurement error, and the calibration correction will not eliminate this. Although evaluation of this scatte $r$ is the basis for estimating the error in $\bar{z}$, we consider the form which this estimate should take.

In this case, $z_{h}=y_{h} / \hat{Y}_{h}$ and $z_{j}=y_{j} / \hat{Y}_{j}$ are correlated, as above, because of the common error (or random variation) in the estimated $\hat{\mathrm{Y}}_{\mathrm{h}}$ and $\hat{Y}_{\mathrm{j}}$. However, this effect is less than a further correlation between $\dot{z}_{h}$ and $z_{j}$ arising from $y_{h}$ 's correlation with $\hat{Y}_{h}$ and $\hat{Y}_{j}$, and similarly for $y_{j}$. That is, the particular error in measuring $y_{h}$ has entered into the normalization estimates $\hat{\mathrm{Y}}_{\mathrm{h}}$ and $\hat{\mathrm{Y}}_{\mathrm{j}}$.

\footnotetext{
* The work which prompted the present investigation is described in Ref. 1.
} 
If each of the $y_{j}{ }^{\prime} s$ has the same error distribution [i.e., $\sigma\left(y_{j}\right)=$ constant], $t$ and if the range of variation of the calibration curve is relatively small, then we might expect to estimate the error in $z$-measurements by the usual estimator

$$
s_{z}^{2}=\frac{1}{\nu_{z}} \sum_{i=1}^{n}\left(z_{i}-\bar{z}\right)^{2} .
$$

If no calibration curve were involved, and the $z_{i}$-values were considered repeated measurements of the same quantity $Z$, then $\sigma_{Z}^{2}$, the squared error in $z$-measurement, would be estimated as $s_{z}^{2}$, and this would be an unbiased estimate if we used $\nu_{z}=n-1$. Then $\bar{z}$ would be an estimate of $Z$, and $\sigma(\bar{z})$, the error in $\bar{z}$, would be estimated with $s(\bar{z})=s_{z} / \sqrt{n}$.

On the other hand, when an analogous kind of $s^{2}$ is used to estimate the scatter of points around a least-squares-fitted curve, the equivalent of (2) is used as an estimate of $\sigma_{z}^{2}$, but $\nu_{z}$ is reduced to $n-1-F$, where $F$ represents the number of fitted parameters used in the curve in addition to the location parameter. As in (2), one degree of freedom is subtracted for the estimation of the location parameter. In total, the number of degrees of freedom, $\nu_{z}$, is reduced from $n$ by $(1+F)$, and this allows for the correlations introduced in using deviations from an estimated curve for calculating $s^{2}$.

In the same way, if estimation of the calibration curve $Y=f(x)$ involves $y_{i}$ 's which also enter $z_{i}$ 's, then one might also expect to reduce $\nu_{z}$ in (2) below $n-1$. However, $\nu_{z}$ would not be reduced by the full amount $F$, since only a fraction $\theta$ of the $y_{i}$ 's are averaged as $z_{i}$ 's. As a rough guess, one might reduce $\nu_{\mathrm{z}}$ to $\nu_{\mathrm{Z}}^{*}=\mathrm{n}-1-\mathrm{F} \theta$.

We have made no attempt to demonstrate this conjecture in a general way. We have, instead, calculated some specific, though typical, cases.

We first consider a straight-line calibration curve. This is simple enough so that the correlation effect can be readily calculated analytically. The measured quantity is $y_{i}$ and the "true" calibration curve is $Y_{i}=\alpha+\beta x_{i}$. The $y_{i}$-values measured at $p$ equally spaced $x_{i}$-values, $x_{i}=1,2,3, \ldots, p$, are used to calculate the estimated line $\hat{Y}_{i}=\hat{\alpha}+\hat{\beta} x_{i}$, using least squares. It is the estimated curve $\hat{\mathrm{Y}}_{\mathrm{i}}$ which is used for calibration calculations.

\footnotetext{
†For example, if each is the same kind.of measurement. We do not explicitly consider a weighted case, where $\dot{\sigma}\left(y_{j}\right)$ varies with $j$, as, e.g., when $y_{j}$ is derived from a counting measurement, hence is calculated from Poisson statistics. Weighting with the Poisson error is justified only if the actual deviations $\left(\Delta y_{j}\right)$ of measured $y_{j}$ 's from the fitted curve $\hat{Y}_{j}=\hat{f}\left(x_{j}\right)$ are consistent with the nominal Poisson errors (e.g., as tested with a chi-square test). If a test shows that the actual $\Delta y_{j}$ 's exceed the Poisson-derived $\sigma\left(y_{j}\right)$ 's, then it may be assumed that non-Poisson sources of error dominate and unweighted $y_{j}$ 's are used. The modification of $v_{z}$ given in Eq. (21) will probably be a useful approximation even where use of weights is justified. Indeed, Examples 3 and 4 support the proposal that results are quite similar when $\sigma\left(y_{j}\right)$ is not constant.
} 
With an odd $\mathrm{p}$, the "true" value at the mid $\mathrm{x}$-value, $\mathrm{x}_{\mathrm{m}}=\frac{1}{2}(\mathrm{p}+1)$, is $\mathrm{Y}_{\mathrm{m}}$. For this case, $\beta$ and $\alpha$ are chosen so the maximum $Y_{i}$-deviation from $\mathrm{Y}_{\mathrm{m}}$ is $\pm 10 \%$. Each $\mathrm{y}_{i}$-measurement is subject to the error $\epsilon_{i}$, a random deviate from a Gaussian distribution with standard deviation $\sigma_{a}$. Then

$$
y_{i}=Y_{i}+\epsilon_{i} \quad(i=1,2,3, \ldots, p) .
$$

Since the $\mathrm{y}_{\mathrm{i}}$-error is independent of $\mathrm{x}_{\mathrm{i}}$, unweighted least squares are appropriate. Least-squares calculation yields the estimates

$$
\hat{\beta}=\frac{S_{x y}}{S_{x x}} \text {, with } S_{x y}=\sum_{i=1}^{p}\left(x_{i}-x_{m}\right) y_{i}, S_{x x}=\sum_{i=1}^{p}\left(x_{i}-x_{m}\right)^{2}
$$

and

$$
\hat{\alpha}=\bar{y}-\hat{\beta} x_{m} \text {, with } \bar{y}=\frac{1}{p} \sum_{i=1}^{p} y_{i}, x_{m}=\frac{1}{p} \sum_{i=1}^{p} x_{i}=\bar{x} \text {. }
$$

All values are to be normalized to the value at $x_{m}$, i.e., $\hat{\mathrm{Y}}_{\mathrm{m}}=\hat{\alpha}+$ $\hat{\beta} \mathbf{x}_{\mathrm{m}}=\overline{\mathrm{y}}$. Although $\overline{\mathrm{x}}$ is a chosen quantity, $\bar{y}$ is a random variable. (i.e.," taking randomly different values in repeated trials)." Let the normalization factor at $x_{i}$ be

$$
\gamma_{i}=\frac{\hat{Y}_{i}}{\hat{Y}_{m}}=\frac{1}{\bar{y}}\left(\hat{\alpha}+\hat{\beta} x_{i}\right)=\frac{1}{\bar{y}}\left[\bar{y}+\hat{\beta}\left(x_{i}-x_{m}\right)\right]=1+\frac{\hat{\beta}}{\bar{y}}\left(x_{i}-x_{m}\right),
$$

so the normalized value is

$$
z_{i}=y_{i} / \gamma_{i}
$$

Then, * with $\Gamma_{i}=Y_{i} / Y_{m}=1+\left(\beta / Y_{m}\right)\left(x_{i}-x_{m}\right) \cong \varepsilon\left(\gamma_{i}\right)$, a propagation of errors calculation gives

$$
\sigma^{2}\left(z_{i}\right)=\frac{\sigma_{a}^{2}}{\Gamma_{i}^{2}}\left\{1+\frac{1}{p} \frac{\beta\left(x_{i}-x_{m}\right)}{Y_{m}}\left[2+\frac{\beta\left(x_{i}-x_{m}\right)}{Y_{m}}\right]-\frac{\left(x_{i}-x_{m}\right)^{2}}{S_{x x}}\right\} .
$$

The maximum value of $\left|\beta\left(\mathrm{x}_{\mathrm{i}}-\mathrm{x}_{\mathrm{m}}\right)\right|$ is $0.1 \mathrm{Y}_{\mathrm{m}}$, so the term in $\{.\} \cong 1$ for reasonably large p. Hence, $\sigma\left(z_{i}\right) / \sigma_{a}$ lies in the range $1 \pm 0.1$.

*We use the usual symbol $E$ for the expectation operator. If $P(x)$ is the probability distribution for $x$, over the range $a \leqq x \leqq b$, then expectation of $x$ is $E(x)-\int_{c}^{b} x P(x)$. $d x$. 
Suppose we average some of the $z_{i}$ 's spread over the range of $x_{i}{ }^{\prime} s$. We choose every fth $z_{i}$-value as $u_{j}$ :

$$
\begin{aligned}
u_{j}: j & =1,2,3, \ldots, n ; \\
i & =f, 2 f, 3 f, \ldots, n f
\end{aligned}
$$

with $n f$ the largest multiple of $f$ in $p$. Then

$$
\bar{u}=\frac{1}{n} \sum_{j=1}^{n} u_{j}
$$

is the average value.

We define some terms arising in later calculations:

$$
\begin{aligned}
& A=\sum_{j=1}^{n} \frac{1}{\Gamma_{j}^{2}} \text {, with } \Gamma_{j}=1+\frac{\beta}{Y_{m}}\left(x_{j}-x_{m}\right) ; \\
& B=\sum_{j=1}^{n} \frac{1}{\Gamma_{j}} ; \quad C=\sum_{j=1}^{n} \frac{x_{j}-x_{m}}{\Gamma_{j}} ; \quad D=\sum_{j=1}^{n} \frac{\left(x_{j}-x_{m}\right)}{\Gamma_{j}^{2}} ; \\
& E=\sum_{j=1}^{n} \frac{\left(x_{j}-x_{m}\right)^{2}}{\Gamma_{j}^{2}} ; \quad S_{x x}=\sum_{j=1}^{p}\left(x_{i}-x_{m}\right)^{2} ; \quad G=\frac{2 \beta}{p Y_{m}} ; \quad H=\frac{\beta^{2}}{p Y_{m}^{2}} .
\end{aligned}
$$

We may consider an average value of $\sigma^{2}\left(u_{j}\right)$, namely,

$$
\overline{\sigma^{2}\left(u_{j}\right)}=\frac{1}{n} \sum_{j=1}^{n} \sigma^{2}\left(u_{j}\right),
$$

and the related quantity

$$
\frac{1}{n} \overline{\sigma^{2}\left(u_{j}\right)}=\frac{1}{n^{2}} \sum_{j=1}^{n} \sigma^{2}\left(u_{j}\right)
$$

From (8), this has the value

$$
\frac{1}{n} \overline{\sigma^{2}\left(u_{j}\right)}=\frac{\sigma_{a}^{2}}{n^{2}}\left\{A+G D+H E-\frac{E}{S_{x x}}\right\} \text {. }
$$

Equation (13), however, does not give the $\overline{\mathrm{u}}$-error, i.e., $\sigma(\overline{\mathrm{u}})$. From a propagation-of-errors calculation which includes the $\left(u_{j}, u_{i}\right)$ correlation, 


$$
\begin{aligned}
\sigma^{2}(\bar{u}) & =\frac{1}{n^{2}}\left[\sum_{j=1}^{n} \sigma^{2}\left(u_{j}\right)+\sum_{i}^{n} \sum_{j}^{n} \operatorname{cov}\left(u_{i}, u_{j}\right)\right] \\
& =\frac{1}{n} \overline{\sigma^{2}\left(u_{j}\right)}+\frac{1}{n^{2}} \sum_{i}^{n} \neq \sum_{j}^{n} \operatorname{cov}\left(u_{i}, u_{j}\right)
\end{aligned}
$$

or

$$
\sigma^{2}(\bar{u})=\frac{\sigma_{a}^{2}}{n^{2}}\left\{A+G B C+H C^{2}-\frac{C^{2}}{S_{x x}}\right\} .
$$

If the $u_{j}$ 's were uncorrelated, then $\operatorname{cov}\left(u_{i}, u_{j}\right)=0$ and

$$
\sigma^{2}(\bar{u})=\frac{1}{n^{2}} \sum_{j=1}^{n} \sigma^{2}\left(u_{j}\right)=\frac{\overline{\sigma^{2}\left(u_{j}\right)}}{n} .
$$

However, since the $u_{j}$ 's are correlated, $\operatorname{cov}\left(u_{i}, u_{j}\right) \neq 0$; hence, (13) and (15) differ.

Example 1. Consider a case with p. $=49, \beta=1 / 8, \alpha=26 \frac{7}{8}$, and

\begin{tabular}{|c|c|c|c|c|}
\hline$n$ & 12 & 16 & 24 & 49 \\
\hline$f$ & 4 & 3 & 2 & 1 \\
\hline A & 12.0190 & 16.0932 & 24.2420 & 49.5158 \\
\hline B & 11.990 & 16.0198 & 24.0803 & 49.0000 \\
\hline C & 2.4796 & -4.7628 & -19.2820 & -41.0903 \\
\hline 0 & -7.0341 & -17.598 & -38.796 & -82.698 \\
\hline E & 2283.276 & 3080.433 & 4683.449 & 9985.946 \\
\hline$S_{x x}$ & 9800 & 9800 & 9800 & 9800 \\
\hline$G$ & $1.7007\left(10^{-4}\right)$ & $1.7007\left(10^{-4}\right)$ & $1.7007\left(10^{-4}\right)$ & $1.7007\left(10^{-4}\right)$ \\
\hline $\mathrm{H}$ & $3.543\left(10^{-7}\right)$ & $3.543\left(10^{-7}\right)$ & $3.543\left(10^{-7}\right)$ & $3.543\left(10^{-7}\right)$ \\
\hline$G D+H E$ & -0.00039 & -0.00190 & -0.00494 & -0.01053 \\
\hline$E / S_{X X}$ & 0.23298 & 0.31433 & 0.47790 & 1.01897 \\
\hline $\mathrm{GBC}+\mathrm{HC}^{2}$ & 0.00506 & -0.01297 & -0.07884 & -0.34182 \\
\hline$c 2 / s_{x x}$ & 0.000627 & 0.00231 & 0.03794 & 0.17229 \\
\hline$\sigma^{2}(\bar{u})$ & 0.08350 & 0.06285 & 0.04188 & 0.020409 \\
\hline$\sigma \frac{2}{a} / n$ & 0.08333 & 0.06250 & 0.04167 & 0.020408 \\
\hline$\frac{\sigma^{2}(\bar{u})}{\sigma_{a}^{2} / n^{2}}$ & 12.0234 & 16.0898 & 24.1252 & 49.0017 \\
\hline$\frac{\sigma^{2}(\bar{u})}{\sigma_{a}^{2} / n}$ & $1+0.0020$ & $1+0.0056$ & $1+0.0052$ & $1+0.00003$ \\
\hline$\frac{\overline{\sigma^{2}\left(u_{j}\right) / n}}{\sigma_{\frac{\gamma}{d}}^{2} / n^{2}}$ & $12-0.214$ & $16-0.2231$ & $24 \cdot 0.241$ & $49-0.5137$ \\
\hline$\frac{\overline{\sigma^{2}\left(u_{j}\right) / n}}{\sigma_{\mathrm{g}}^{2 / n}}$ & $1-0.0179$ & $1-0.0127$ & $1-0.0100$ & $1-0.0105$ \\
\hline
\end{tabular}
$\sigma_{\mathrm{a}}=1$. Then $\mathrm{x}_{\mathrm{m}}=25$ and $\mathrm{Y}_{\mathrm{m}}=30$. We compute for $\mathrm{n}=12,16,24$, and 49, with the results in Table I. For $n=12, f=4$ (i.e., every fourth $z_{j}$ is $\left.a u_{j}\right)$; for $n=16, f=3$, etc. 
The correlation effect does cause some difference between the correct value $\sigma^{2}(\bar{u})$ and the result $\overline{\sigma^{2}\left(u_{j}\right)} / \mathrm{n}$ derived by neglecting correlation. In this symmetric case, with $u_{j}$ 's chosen over the whole range of $x$-values, the correlation effect is weak. If we neglect it, the putative error in $\bar{u}$, given by $\overline{\sigma^{2}\left(u_{j}\right)} / \mathrm{n}$, undershoots $\sigma^{2}(\bar{u})$ by only $2 \%$.

We note that $\sigma\left(u_{j}\right) \cong \sigma_{a} / \Gamma j$ i.e., the error in $u_{j}$ varies with $x_{j}$ to the extent of $\pm 10 \%$. This is in contrast to the constant error in $y$ [i.e., $\left.\sigma\left(y_{j}\right)=\sigma_{a}\right]$. Consider, on the other hand, $\sigma^{2}(\bar{u})$. Suppose that $y_{i}$ did not vary with $\mathrm{x}_{\mathrm{i}}$ (i.e., $\beta \cong 0$ ). Then the desired average would be $\overline{\mathrm{y}}$, whose error is given by $\sigma^{2}(\bar{y})=\sigma_{a}^{2} / \mathrm{n}$. We note that $\sigma^{2}(\bar{u}) \cong \sigma_{a}^{2} / n$, i.e., when the $\mathrm{y}_{j}$ 's used in the $\mathrm{u}_{j}$ 's are spread out along the $\mathrm{x}$-axis, the variation of $\sigma\left(u_{j}\right)$ above and below $\sigma_{\mathrm{a}}$ averages out in $\sigma(\overline{\mathrm{u}})$. Almost the same average occurs in $\overline{\sigma^{2}\left(u_{j}\right)} / \mathrm{n}$.

How is $\sigma^{2}(\bar{u})$ estimated? If $y_{i}$ did not vary with $x_{i}$ (i.e., $\beta=0$ ), then $\Gamma_{i} \equiv 1$ and $\sigma^{2}(\bar{u})$ is estimated as

$$
\mathrm{s}^{2}(\overline{\mathrm{u}})=\frac{\mathrm{s}_{\mathrm{a}}^{2}}{\mathrm{n}}
$$

with

$$
\mathrm{s}_{\mathrm{a}}^{2}=\frac{\mathrm{s}_{\mathrm{u}}}{\nu_{\mathrm{u}}}
$$

and

$$
S_{u}=\sum_{i=1}^{n}\left(u_{i}-\bar{u}\right)^{2}, \quad \bar{u}=\frac{1}{n} \sum_{i=1}^{n} u_{i}
$$

with

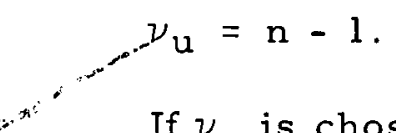

If $\nu_{\mathrm{u}}$ is chosen as $(\mathrm{n}-1)$, then the expectation value of $\mathrm{s}_{\mathrm{a}}^{2}$ is $\varepsilon\left(\mathrm{s}_{\mathrm{a}}^{2}\right)=$ $\left(1 / \nu_{u}\right) e\left(S_{u}\right)=\left(1 / \nu_{u}\right)\left(\nu_{u} \sigma_{a}^{2}\right)=\sigma_{a}^{2}$, and $E\left[\dot{s}^{2}(\bar{u})\right]=e\left(s_{a}^{2}\right) / n=\sigma_{a}^{2} / n=\sigma^{2}(\bar{u})$. Then $s_{a}^{2}$ and $s^{2}(\bar{u})$ are unbiased estimates of $\sigma_{a}^{2}$ and $\sigma^{2}(\bar{u})$, respectively.

In the case considered, with a linear calibration curve, $S_{u}$ calculated as in (18) has an expectation value given by

$\frac{e\left(S_{u}\right)}{\sigma_{a}^{2}}=\nu_{u}=\frac{n-1}{n} A+G\left[D-\frac{1}{n} B C\right]+H\left[E-\frac{1}{n} C^{2}\right]-\frac{1}{S_{x x}}\left[E-\frac{1}{n} C^{2}\right]$ 
Example 2. For the same case as in Example 1. The values of $\left(A, B, \overline{C, D}, E, G, H\right.$, and $S_{X x}$ ) are the same as in Table I. The remainder of the calculations are shown in Table II, with $F=1$ and $\theta=n / p=n / 49$.

TABLE II

\begin{tabular}{|c|c|c|c|c|}
\hline $\mathrm{n}$ & 12 & 16 & 24 & 49 \\
\hline$n-1$ & 11 & 15 & 23 & 48 \\
\hline $\bar{n}$ & $\overline{12}$ & $\overline{16}$ & $\overline{24}$ & $\overline{49}$ \\
\hline$A$ & 12.0190 & 16.0932 & 24.2420 & 49.5158 \\
\hline $\mathrm{A} / \mathrm{n}$ & 1.0016 & 1.0058 & 1.0101 & 1.0105 \\
\hline$\theta=\mathrm{n} / \mathrm{p}$ & $12 / 49$ & $16 / 49$ & $24 / 49$ & 1 \\
\hline$\frac{n-1}{n} A$ & 11.0174 & 15.0873 & 23.2319 & 48.5052 \\
\hline$G\left[D \cdot-\frac{1}{n} B C\right]$ & -0.00161 & -0.00218 & -0.00331 & -0.00705 \\
\hline $\mathrm{H}\left[\mathrm{E}-\frac{1}{\mathrm{n}} \mathrm{C}^{2}\right]$ & 0.00081 & 0.00109 & 0.00165 & 0.00353 \\
\hline$E / S_{x x}$ & 0.23298 & 0.31433 & 0.47790 & 1.01897 \\
\hline$\frac{1}{S_{x x}}\left[E-\frac{1}{n} C^{2}\right]$ & 0.23293 & 0.31419 & 0.47632 & 1.01546 \\
\hline $\mathrm{n} / 49$ & 0.24490 & 0.32653 & 0.48980 & 1.0000 \\
\hline$\frac{e\left(S_{\mathrm{u}}\right)}{\sigma_{\mathrm{a}}^{2}}=\nu_{\mathrm{u}}$ & 10.7837 & 14.7721 & 22.7539 & 47.4863 \\
\hline$\nu_{\mathrm{u}}^{*}=\mathrm{n}-1-\mathrm{F} \theta$ & 10.7551 & 14.6735 & 22.5102 & 47 \\
\hline$\frac{\nu_{\mathrm{u}}}{\nu_{\mathrm{u}}^{*}}$ & 1.00266 & 1.00672 & 1.01083 & 1.01035 \\
\hline
\end{tabular}

Some observations from Example 2:

1. The dominant terms are $(\mathrm{A} / \mathrm{n})(\mathrm{n}-1)$ and $-\mathrm{E} / \mathrm{S}_{\mathrm{Xx}}$.

2. $A$ is very close to $\underline{n}$ in value. It differs because the terms $1 / \Gamma_{j}^{2}$ below unity do not quite balance the above-unity terms in the average. The difference $[(\mathrm{A} / \mathrm{n})-1]$ will be smaller if the maximum value of $\left|Y_{\mathbf{i}}-\mathrm{Y}_{\mathrm{m}}\right|$ is $<10 \%$.

3. The term $(A / n)(n-1)$ is analogous to the quantity $(n-1)$, appropriate when no calibration curve is necessary (i.e., $\beta=0$ ). 
4. If we discount the effect of $\Gamma_{j}^{2}$ (since these tend to average out), then $E$ has the same form as $S_{x x}$, but with less terms, in the ratio $n / p$. Since the $x$-values are spread over almost the same range in $E$ and $S_{x x}$, we may expect that $\mathrm{E} / \mathrm{S}_{\mathrm{xx}} \cong \mathrm{n} / \mathrm{p}$, and this is indeed borne out in Table II (since $\left.E \gg C^{2} / n\right)$.

5. Fitting a straight line removes only one more degree of freedom than the location parameter $\left(Y_{m}\right)$, so $F=1$ and $\nu_{u} \cong(A / n)(n-1)-n / p$.

These results suggest that our previous guess was close. As a further check, we consider a model in which the $y_{i}$-error is not constant, but the percentage error is. Then $\sigma^{2}\left(y_{i}\right)=\sigma_{0}^{2} Y_{i}^{2}$. Details analogous to (13), (15), and (20) are calculated by the same methods, but are not given here. Numerical results analogous to those of Examples 1 and 2 are shown in Examples 3 and 4.

Example 3. As in Example 1, except that $\sigma^{2}\left(y_{i}\right)=\sigma_{0}^{2} Y_{i}^{2}$. Like Example $1, \hat{Y}_{i}=\hat{\alpha}+\hat{\beta} x_{i}$ is estimated with an unweighted least-squares calculation. Since $\sigma^{2}\left(y_{i}\right)$ is not constant, $(\hat{\alpha}, \hat{\beta})$ are unbiased estimates, but are not the minimum variance estimates derivable from weighted least squares. The calculation, however, is simplified, because (4) and (5) still hold, although the analogs of (8), (13), (15), and (20) are changed. Numerical results are shown in Table III. Variance values are referred to $\sigma_{M}^{2}=\sigma_{0}^{2} Y_{M}^{2}$, where $\sigma_{M}=\sigma\left(y_{M}\right)=$ error at the midpoint $x_{i}=x_{25}=25$. For this example, we set $\sigma_{M}=1$.

TABLE III

\begin{tabular}{ccccc}
\hline $\mathrm{n}$ & 12 & 16 & 24 & 49 \\
\hline $\mathbf{f}$ & 4 & 3 & 2 & 1 \\
$\sigma^{2}(\overline{\mathrm{u}})$ & 0.08330 & 0.06254 & 0.04173 & 0.020480 \\
$\sigma_{\mathrm{M}}^{2} / \mathrm{n}$ & 0.08333 & 0.06250 & 0.04167 & 0.020408 \\
$\frac{\sigma^{2}(\overline{\mathrm{u}})}{\sigma_{\mathrm{M}}^{2} / \mathrm{n}}$ & $1-0.00043$ & $1+0.00059$ & $1+0.00144$ & $1+0.00350$ \\
$\frac{\sigma^{2}\left(\mathrm{u}_{\mathrm{j}}\right) / \mathrm{n}}{\sigma_{\mathrm{M}}^{2} / \mathrm{n}}$ & $1-0.0196$ & $1-0.0194$ & $1-0.0193$ & $1-0.0201$ \\
\hline$\frac{\varepsilon\left(\mathrm{S}_{\mathrm{u}}\right)}{\sigma_{\mathrm{M}}^{2}}=\nu_{\mathrm{u}}$ & 10.7651 & 14.6885 & 22.5357 & 47.0112 \\
$\mathrm{n}-1-\mathrm{F} \theta=\nu_{\mathrm{u}}^{*}$ & 10.7551 & 14.6735 & 22.5102 & 47 \\
\hline$\frac{\nu_{\mathrm{u}}}{\nu_{\mathrm{u}}^{*}}$ & 1.00096 & 1.00102 & 1.00113 & 1.00024 \\
\hline
\end{tabular}


Example 4. As in Example 3, except that the line is estimated with weighted least squares, which yields the minimum variance linear unbiased estimates $\left(\hat{\alpha}, \hat{\beta}, \hat{Y}_{i}\right)$. The weights are $w_{i}=\sigma_{0}^{2} / \sigma^{2}\left(y_{i}\right)=1 / Y_{i}^{2}$. Equations (4) and (5) are appropriately modified. The analogs of (8), (13), (15), and (20) are formally similar to these relations. Variance values are referred to $\sigma_{M}^{2}=\sigma_{0}^{2} Y_{M}^{2}$, where $\sigma_{M}=\sigma\left(y_{M}\right)=$ error at the weighted mean $x_{M}=23.7912$ $\left(Y_{M}=29.7912\right)$. For this example, we set $\sigma_{M}=1$. Numerical results are shown in Table IV.

TABLE IV

\begin{tabular}{|c|c|c|c|c|}
\hline $\mathrm{n}$ & 12 & 16 & 24 & 49 \\
\hline$f$ & 4 & 3 & 2 & 1 \\
\hline$\sigma^{2}(\bar{u})$ & 0.08329 & 0.06254 & 0.04174 & 0.020480 \\
\hline$\sigma_{M}^{2} / n$ & 0.08333 & 0.06250 & 0.04167 & 0.020408 \\
\hline$\frac{\sigma^{2}(\overline{\mathrm{u}})}{\sigma_{\mathrm{M}}^{2} / \mathrm{n}}$ & $1-0.00046$ & 1.00067 & 1.00171 & 1.00350 \\
\hline$\frac{\overline{\sigma^{2}\left(u_{j}\right) / n}}{\sigma_{M}^{2} / n}$ & $1-0.0192$ & $1-0.0193$ & $1-0.0195$ & $1-0.0203$ \\
\hline$\frac{\varepsilon\left(S_{\mathrm{u}}\right)}{\sigma_{M}^{2}}=\nu_{\mathrm{u}}$ & 10.7706 & 14.6906 & 22.5309 & 47.000001 \\
\hline $\mathrm{n}-\mathrm{l}-F \theta=\nu_{\mathrm{u}}^{*}$ & 10.7551 & 14.6735 & 22.5102 & 47 \\
\hline$\frac{\nu_{\mathrm{u}}}{\nu_{\mathrm{u}}^{*}}$ & 1.00144 & 1.00117 & 1.00092 & 1.00000 \\
\hline
\end{tabular}

Since the agreement between conjecture and calculation is just as good for the examples, it is reasonable to suppose that the conjecture is fairly insensitive to the error model. We propose tentatively that, in general, we will be fairly close if we take

$$
\nu_{\mathrm{u}}^{*}=\mathrm{n}-\mathrm{l}-\mathrm{F} \theta
$$

where

$$
\begin{aligned}
& \mathrm{n}=\text { number of } \mathrm{u}_{\mathrm{i}} \text {-values; }
\end{aligned}
$$

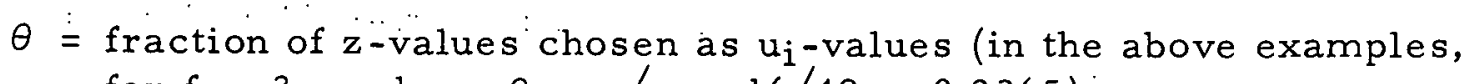

$$
\begin{aligned}
& \text { for } f=3 \text {, we have } \theta=n / p=16 / 49=0.3265) ; \text {; } \\
& F=\text { a quantity one less than the number of degrees of freedom re- } \\
& \text { moved in the least squares calculation (in Example.2, } \\
& F=2-1=1 \text { ). }
\end{aligned}
$$


As usual, we. remove one degree of freedom because we measure deviations from $\bar{u}$. We then remove.a fraction of the remaining degrees of freedom lost in the least-squares averaging. The fraction is that part of the $\mathrm{yi}_{\mathrm{i}}$ 's used in the calculation of the calibration curve which are also averaged into $\bar{u}$.

Our error estimate is then

$$
s^{2}(\bar{u})=\frac{s_{u}^{2}}{n}
$$

with

$$
\mathrm{s}_{\mathrm{u}}^{2}=\frac{\mathrm{s}_{\mathrm{u}}}{\nu_{\mathrm{u}}^{*}} .
$$

Here $\nu_{u}^{*}$ is not exactly equal to the correct value $\nu_{u}$ in Table II. In general, for more complex cases, we shall not expect $\nu_{u}^{*}$ to be an accurate estimate of the correct $\nu_{u}$, i.e., one with essentially no bias. Such accuracy is, indeed, unnecessary, because of the built-in variability of the error estimate $s_{u}$. Because $s_{u}$ as an estimate of a standard deviation $\sigma_{u}$ is highly variable ${ }^{\dagger}$ in small samples, we are not concerned if $\nu_{u}^{*}$ is not exactly what a complete analysis would predict $\nu_{\mathrm{u}}$ to be. We shall be satisfied if $\nu_{\mathrm{u}}^{*}$ is reasonably close to $\nu_{\mathrm{u}}$ and if it is aconservative $e^{-}$stimate, i.e., $\nu_{\mathrm{u}}^{*}<\nu_{\mathrm{u}}$. Then, from (23), $\mathrm{s}_{\mathrm{u}}^{2}$ will tend to be a little larger than if $\nu_{\mathrm{u}}$ were used. From an experimenter's viewpoint, a small overestimate of the error is always acceptable.

Equations (21), (22), and (23) have been suggested from the results calculated for a simple calibration line. However, it is not often that a calibration curve is as simple as a straight line. To investigate the effect of nonmonotonic calibration curves (i.e., with maxima and minima), we considered $Y_{i} \doteq f\left(x_{i}\right)$ to be a polynomial.

Since an analytical calculation threatened to be too heavy in algebra, we decided to explore the effect with a Monte Carlo calculation (i.e., a random-sampling experiment). Before investigating the polynomial, we tried the straight line case with constant $\sigma^{2}\left(y_{i}\right)$, t for which we could compare random sampling results with (15) and (20).

\footnotetext{
That is, takes on quite different values in repetitions of the identical experiment. The great variability of $s_{\mathrm{u}}$ is best illustrated with an experiment not involving a calibration curve and in which the random error in $\mathrm{u}$-measurements has a Gaussian distribution with standard deviation $\sigma_{\mathrm{u}}$. Then the $\mathrm{s}_{\mathrm{u}}^{2}$-value [calculated as in (18) and $(19)]$ is a random quantity with a chi-square distribution having [std. dev. of $\left.s_{u}^{2}\right] /\left[\right.$ Mean of $\left.s_{u}^{2}\right]=$. $\left(2 / \nu_{\mathrm{u}}\right)^{1 / 2}$ It is only when $v_{\mathrm{u}}$ is as large as 32 that the [std. dev. of $\mathrm{s}_{\mathrm{u}}^{2}$ ] becomes as small as $1 / 4$ of $\sigma_{\mathrm{u}}^{2}$, the mean of $s_{u}^{2}$; hence [std. dev: of $s_{u}$ ] becomes approximately $1 / 8$ of $\sigma_{u}$. This means that with $v_{u}=32$, we would not be surprised if an experimental $s_{\mathrm{u}}$-value deviated by $12 \%$ (or even more) from $\sigma_{\mathrm{u}}$.

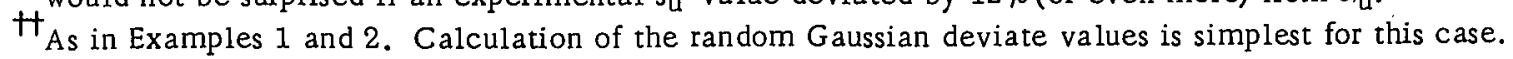


We chose the line in Examples 1 and $2: Y_{i}=\alpha+\beta x_{i}=Y_{m}+$ $\beta\left(x_{i}-x_{m}\right)=30+\frac{1}{8}\left(x_{i}-25\right)$, for $x_{i}=1,2, \ldots, 49$. To each $Y_{i}$ was added a random Gaussian deviate* from a distribution with mean zero and $\sigma_{a}=1$.

The unweighted-least-squares parameter estimates $\hat{\mathrm{Y}}_{\mathrm{m}}=\overline{\mathrm{y}}$ and $\hat{\beta}=S_{x y} / S_{x x}\left[\right.$ in (4) and (5)] were calculated for the line. Then $\gamma_{i}$ and $z_{i}=u_{i}$ were calculated for every fth point; $\bar{u}$ and $S_{u}$ were then evaluated. Anumber of such lines were calculated in batches, and in each batch, $r$ such lines were computed; then the quantities

$$
\overline{S_{u}}=\frac{1}{r} \sum_{j=1}^{r} S_{u}(j)
$$

and

$$
s^{2}(\bar{u})=\frac{1}{r-1} \sum_{j=1}^{r}\left(\bar{u}_{j}-\overline{\bar{u}}\right)^{2}, \quad \text { with } \overline{\bar{u}}=\frac{1}{r} \sum_{j=1}^{r} \bar{u}_{j}
$$

were computed. $\overline{S_{u}}$ is an unbiased estimate of $\sigma_{\mathrm{a}}^{2} \nu_{\mathrm{u}}=\nu_{\mathrm{u}}\left(\right.$ since $\left.\sigma_{\mathrm{a}}^{2}=1\right)$; if $\underline{r}$ is large enough, the deviation of $\overline{S_{u}}$ from $\nu_{u}$ should be small. $s^{2}(\bar{u})$ is an unbiased estimate of $\sigma^{2}(\bar{u})$ and should be close to it if $\underline{r}$ is large enough.

Likely deviations of the Monte Carlo results from the expectation values may be calculated. We take the distribution of both $\overline{S_{u}}$ and $s^{2}(\bar{u})$ as approximately based on chi-square distributions. (They are exactly based on chi-square when $\beta=0$; hence $\Gamma_{i} \equiv 1$.) Then

$$
\begin{aligned}
& \text { mean of } \overline{S_{u}}=e\left\{\overline{S_{u}}\right\}=\psi_{u} ; \\
& \text { variance of } \overline{S_{u}}=\operatorname{var}\left\{\overline{S_{u}}\right\}=\sigma^{2}\left(\overline{S_{u}}\right)=\frac{2 \nu_{u}}{r},
\end{aligned}
$$

where variance $=(\text { standard deviation })^{2}$. Similarly,

$$
\begin{aligned}
& \text { mean of } s^{2}(\bar{u})=e\left\{s^{2}(\bar{u})\right\}=\sigma^{2}(\bar{u}) \\
& \text { variance of } s^{2}(\bar{u})=\operatorname{var}\left\{s^{2}(\bar{u})\right\}=\frac{2 \sigma^{4}(\bar{u})}{r-1} .
\end{aligned}
$$

If $q$ batches are computed, then the estimates are improved by averaging over the batches:

$$
\overline{\overline{\mathrm{s}_{\mathrm{u}}}}=\frac{1}{\mathrm{q}} \cdot \sum_{\eta=1}^{\mathrm{q}} \overline{\mathrm{s}_{\mathrm{u}}}(\eta)
$$

\footnotetext{
*For a description and discussion of the procedure, see Appendix A.
} 
and

$$
\overline{s^{2}(\bar{u})}=\frac{1}{q} \sum_{\eta=1}^{q} s_{\eta}^{2}(\bar{u}) .
$$

Then

$$
\begin{aligned}
& e\left\{\overline{\overline{\mathrm{S}_{\mathrm{u}}}}\right\}=\nu_{\mathrm{u}} \\
& \operatorname{var}\left\{\overline{\overline{s_{u}}}\right\}=\frac{2 \nu_{u}}{r q}=v_{S} ; \\
& \frac{\sigma\left\{\overline{\overline{S_{u}}}\right\}}{\varepsilon\left\{\overline{\overline{\bar{s}_{u}}}\right\}}=\frac{\sqrt{v_{S}}}{\nu_{u}}=\sqrt{\frac{2}{r q \nu_{u}}} \\
& \varepsilon\left\{\overline{s^{2}(\bar{u})}\right\}=\sigma^{2}(\bar{u}) ; \\
& \operatorname{var}\left\{\overline{s^{2}(\bar{u})}\right\}=\frac{2 \sigma^{4}(\bar{u})}{q(r-1)}=V_{s} ; . \\
& \frac{\sigma\left\{\overline{s^{2}(\bar{u})}\right\}}{E\left\{\overline{s^{2}(\bar{u})}\right\}}=\frac{\sqrt{V_{s}}}{\sigma^{2}(\bar{u})}=\sqrt{\frac{2}{q(r-1)}} .
\end{aligned}
$$

\begin{tabular}{|c|c|c|c|c|c|c|c|}
\hline$n$ & $\overline{s^{2}(\bar{u})}$ & $\sigma^{2}(\bar{u})=\mathcal{E}\left\{s^{2}(\bar{u})\right\}^{(b)}$ & $\Delta\left(s^{2}\right)=\overline{s^{2}(\bar{u})}-\sigma^{2}(\bar{u})$ & $\begin{array}{c}\% \text { Deviation } \\
100 \frac{\Delta\left(s^{2}\right)}{\sigma 2(\bar{u})}\end{array}$ & $\begin{array}{l}\text { Std. Dev. } \\
{\sqrt{V_{S}}}^{(c)}\end{array}$ & ${\frac{100{\sqrt{V_{s}}}^{2}}{\sigma^{2}(\mathrm{u})}}^{(\mathrm{d})}$ & $\frac{\Delta\left(s^{2}\right)}{\sqrt{V_{s}}}$ \\
\hline $\begin{array}{l}12 \\
16 \\
24 \\
49\end{array}$ & $\begin{array}{l}0.08447 \\
0.06273 \\
0.04258 \\
0.02060\end{array}$ & $\begin{array}{l}0.08350 \\
0.06285 \\
0.04188 \\
0.02041\end{array}$ & $\begin{array}{c}0.00097 \\
-0.000126 \\
0.00070 \\
0.000193\end{array}$ & $\begin{array}{l}1.16 \% \\
0.20 \% \\
1.67 \% \\
0.95 \%\end{array}$ & $\begin{array}{l}0.000885 \\
0.000666 \\
0.000444 \\
0.000216\end{array}$ & $\begin{array}{l}1.06 \% \\
1.06 \% \\
1.06 \% \\
1.06 \%\end{array}$ & $\begin{array}{r}1.10 \\
-0.19 \\
1.58 \\
0.89\end{array}$ \\
\hline & $\begin{array}{l}q=180 . \\
\text { ble } 1 . \\
(36) . \\
(37)\end{array}$ & . & & & & & ; \\
\hline
\end{tabular}

Lines were computed in groups of $r=100$ per batch. The Gaussian deviates used were identical for each of the cases: $n=12,16,24,49$. With $q=180$, the results are shown in Tables V and VI. The Monte Carlo results evidently checked satisfactorily with the known expected values within the known variability.*

TABLE V. Monte Carlo Results for Linear Case ${ }^{(a)}$

\footnotetext{
* As a further check on the reliability of the method, with the $q=180$ batches divided into 18 batches of 10 each, the $\Delta$-values were divided by the appropriate $\sqrt{V}$-values $\left(q^{\prime}=10\right)$, squared, and summed to give values of chi-square (18 d.o.f.). Standard chi-square tables indicated the experimental chi-square values were all less than the tabulated chi-square value at the $20 \%$ probability level.
} 
TABLE VI. Monte Carlo Results for Linear Case ${ }^{(a)}$

\begin{tabular}{|c|c|c|c|c|c|c|c|c|}
\hline$n$ & $\overline{\overline{S_{u}}}$ & $u_{u}=\varepsilon\left(\overline{\overline{S_{u}}}\right)(b)$ & $\Delta \overline{\left(\overline{s_{u}}\right)}=\overline{\overline{s_{u}}}-v_{u}$ & $\begin{array}{l}\% \text { Deviation } \\
100 \frac{\Delta\left(\overline{\bar{S}_{u}}\right)}{v_{u}}\end{array}$ & $\begin{array}{l}\text { Std. Dev. } \\
\sqrt{V_{S}}(c)\end{array}$ & $\frac{100 \sqrt{V_{S}}}{v_{u}}$ & $\frac{\Delta\left(\overline{\overline{S u}^{\prime}}\right)}{\sqrt{{\sqrt{V_{S}}}^{(d)}}}$ & $\frac{\overline{\bar{S}}_{u}}{v_{u}^{o}}{ }^{(e)}$ \\
\hline 12 & 10.7583 & 10.7837 & -0.0254 & $-0.24 \%$ & 0.0346 & $0.32 \%$ & -0.73 & 1.0003 \\
\hline 16 & 14.7676 & 14.7721 & -0.0045 & $-0.031 \%$ & 0.0405 & $0.27 \%$ & -0.11 & 1.0064 \\
\hline 24 & 22.7726 & 22.7539 & 0.0187 & $0.082 \%$ & 0.0503 & $0.22 \%$ & 0.37 & 1.0117 \\
\hline 49 & 47.4704 & 47.4863 & -0.0159 & $-0.034 \%$ & 0.0726 & $0.15 \%$ & -0.22 & 1.0100 \\
\hline
\end{tabular}

The effect of estimating the calibration curve should be accentuated with many estimated parameters. We considered an 8 th-order polynomial, one with eight zeroes within the previously used range, $x=1, \ldots, 49$. For our purposes, the exact form was not critical, but it was desired to keep extreme excursions to the order of $\pm 10 \%$ of the mean value; in addition, the various extreme excursions were not to differ much in magnitude, and the zeroes were to be spread as broadly as possible over the $\mathrm{x}$-range.

Some trial and error was necessary, + since it is not possible to construct an $\underline{n}$ th-order polynomial with $n$ zeroes in a fixed range, while controlling both position of zeroes and amplitudes of extrema. Some control over the root values was necessary to avoid constructing a polynomial that was too symmetrical. With initial guesses for $r_{i}$ in $Y=\left(x-r_{1}\right)\left(x-r_{2}\right) \ldots$ $\left(x-r_{8}\right)$, a computer-drawn plot made evident the displacements necessary for the roots. A few iterations led to a satisfactory polynomial. Normalization and addition of 30 led to Fig. 1, with coefficients as given in Table VII. A similar process yielded a fourth-order polynomial (see Fig. 2 and Table VII).

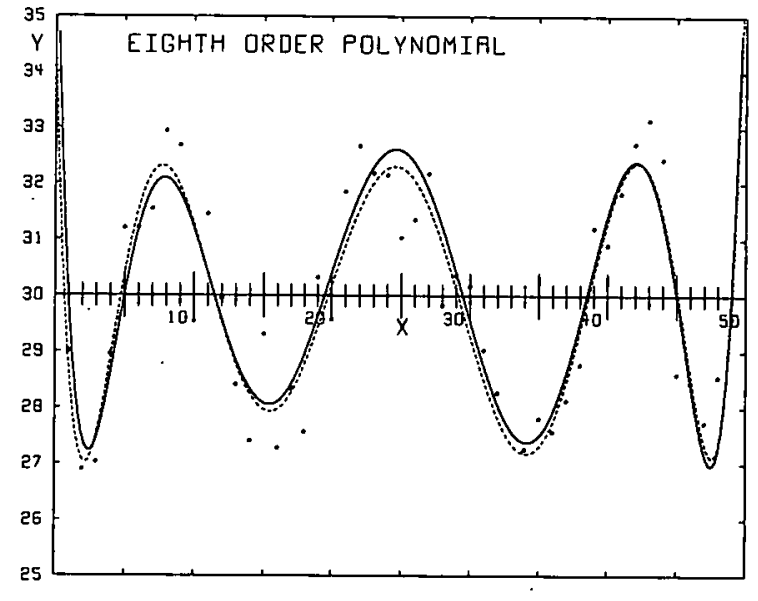

Fig. 1

The Solid Curve is the Constructed 8th-order-polynomial "True Calibration Curve." The points correspond to a typical case in the construction of one "experimental calibration run," that is, each point represents a random (error-containing) measurement at the corresponding $x$-value (an integer), and is derived by adding a random Gaussian deviate (unit standard deviation) to the ordinate of the solid curve. The dotted curve is the least-squares-fitted "experimental calibration curve" calculated from these points.

$121-4921$

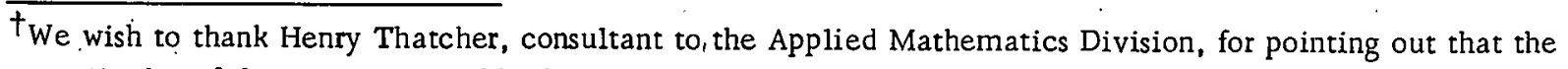
amplitudes of the extrema could be kept approximately the same by placing more roots near the boundaries $(x=1$ and $x=49)$ than in the center.
} 
TABLE VII. Polynomials as Basis for Calibration Curves ${ }^{a}$

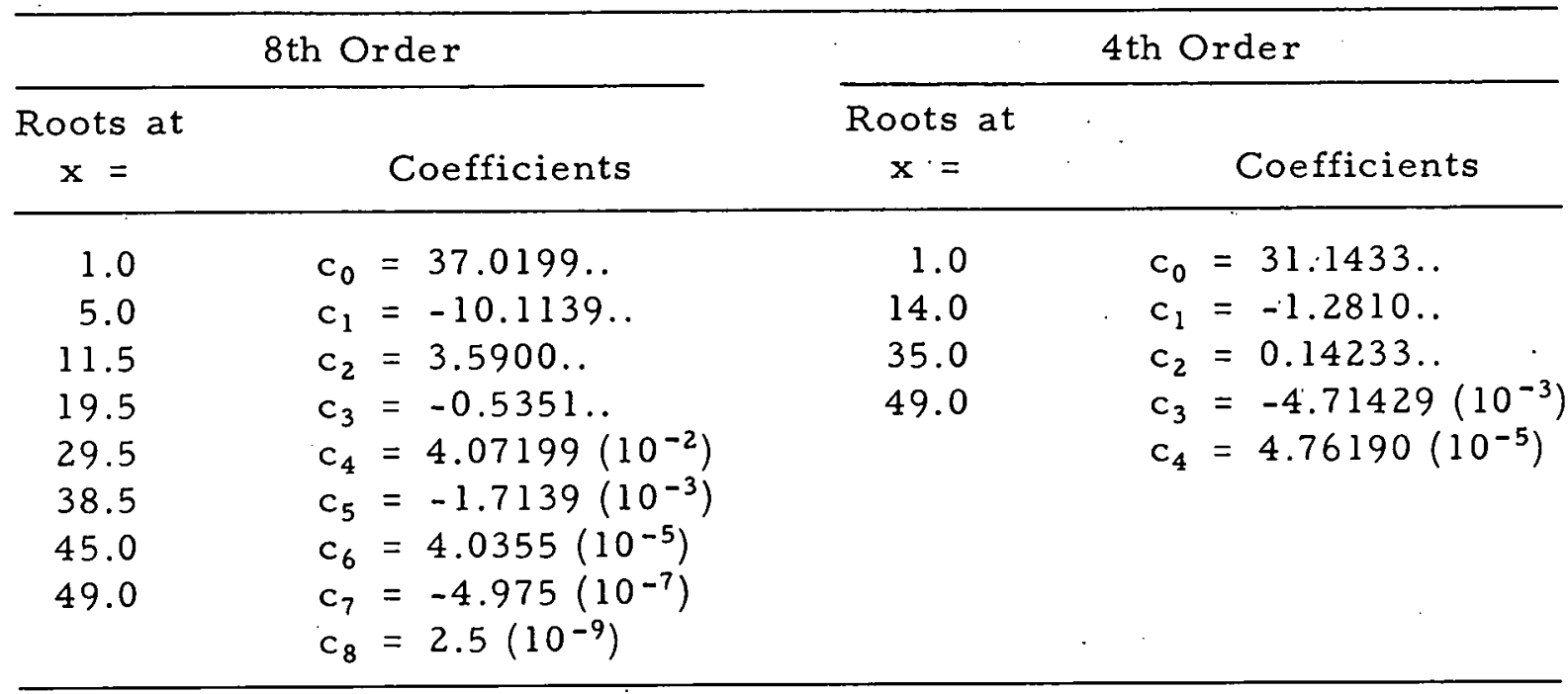

$a_{h}(x)=c_{0}+c_{1} x+c_{2} x^{2}+\ldots$

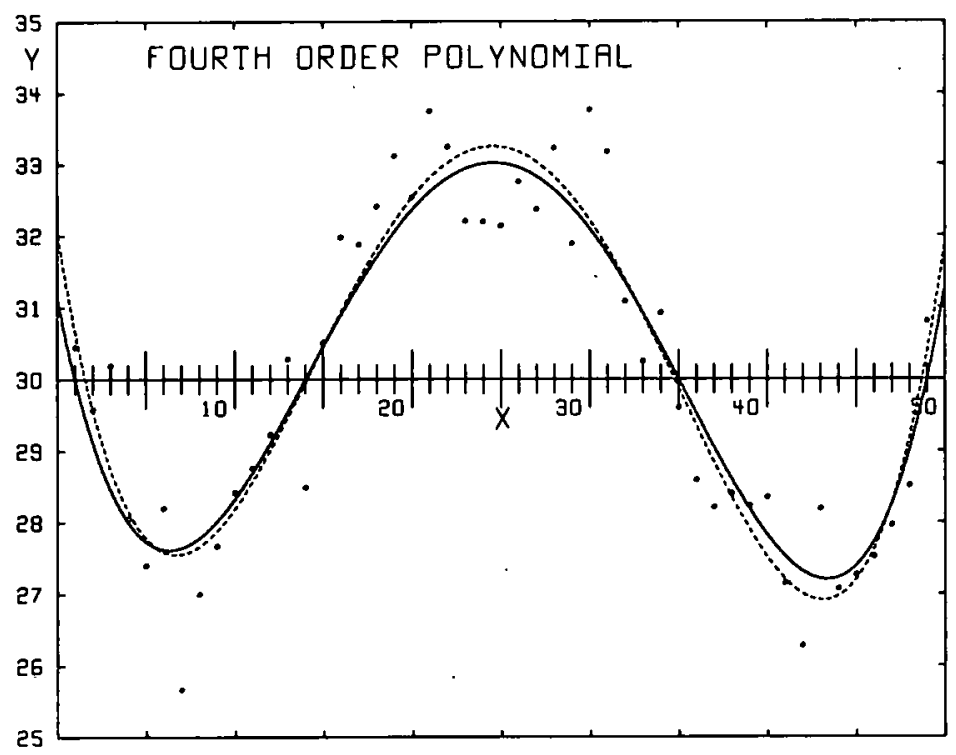

Fig. 2

As in Fig. 1, for a 4th-orderpolynomial Calibration Curve

The Monte Carlo sampling procedure was the same as that used with the straight-line curve. We considered $\sigma\left(y_{i}\right)$ to be constant; hence, to $Y_{i}=c_{0}+c_{1} x_{i}+c_{2} x_{i}^{2}+\ldots$, calculated at each $x_{i}=1,2, \ldots, 49$, was added a random Gaussian deviate $\epsilon_{i}$ to give $y_{i}=Y_{i}+\cdot \epsilon_{i}$. From the 49 sets $\left(x_{i}, y_{i}\right)$ were derived unweighted least-squares estimates $\hat{c}_{0}, \hat{c}_{1}$, $\hat{c}_{2}, \ldots$, and at each $x_{i}$ the calibration curve was estimated as $\hat{Y}_{i}=\hat{c}_{0}+$ $\hat{c}_{1} x_{i}+\hat{c}_{2} x_{i}^{2}+\ldots$. For every fth point, $\gamma_{i}$ was evaluated as in (6) and $z_{i}$ as in (7). Then $\dot{\mathrm{u}}$ and $S_{u}$ were calculated as in (18), and $\overline{S_{u}}$ and $s^{2}(\bar{u})$ as in (24) and (25). Results are shown in Tables VIII and IX. $\overline{\overline{\mathrm{S}_{\mathrm{u}}}}$, an estimate of the appropriate $\nu_{\mathrm{u}}$, exceeds $\nu_{\mathrm{u}}^{*}$, but relatively modestly. 
TABLE VIrI. Monte Carlo Results for 4th-order-polynomial Calibration Curve

\begin{tabular}{lcccccc}
\hline $\mathrm{n}$ & $\overline{\mathrm{s}^{2}(\overline{\mathrm{u}})}$ & $\frac{\sigma_{\mathrm{a}}^{2}}{\mathrm{n}}$ & $\frac{\overline{\mathrm{s}^{2}(\overline{\mathrm{u}})}}{\sigma_{\mathrm{a}}^{2} / \mathrm{n}}$ & $\overline{\overline{\mathrm{S}}}_{\mathrm{u}}$ & $\nu_{\mathrm{u}}^{*}=\mathrm{n}-1-\mathrm{F} \theta$ & $\frac{\overline{\overline{\mathrm{S}}}_{\mathrm{u}}}{\nu_{\mathrm{u}}^{*}}$ \\
\hline 12 & 0.08408 & 0.08333 & 1.009 & 10.2396 & $: 10.0204$ & 1.022 \\
16 & 0.06309 & 0.06250 & 1.009 & 13.9889 & 13.6939 & 1.022 \\
24 & 0.04216 & 0.04167 & 1.012 & 21.4668 & 21.0408 & 1.020 \\
49 & 0.02093 & 0.02041 & 1.026 & 44.5249 & 44.0000 & 1.012 \\
\hline
\end{tabular}

TABLE IX. Monte Carlo Results for 8th-order-polynomial Calibration Curve

\begin{tabular}{lcccccc}
\hline $\mathrm{n}$ & $\overline{\mathrm{s}^{2}(\overline{\mathrm{u}})}$ & $\frac{\sigma_{\mathrm{a}}^{2}}{\mathrm{n}}$ & $\frac{\mathrm{s}^{2}(\overline{\mathrm{u}})}{\sigma_{\mathrm{a}}^{2} / \mathrm{n}}$ & $\overline{\overline{\mathrm{S}}}_{\mathrm{u}}$ & $\nu_{\mathrm{u}}^{*}=\mathrm{n}-1-\mathrm{F} \theta$ & $\frac{\overline{\overline{\mathrm{S}}}_{\mathrm{u}}}{\nu_{\mathrm{u}}^{*}}$ \\
\hline 12 & 0.08349 & 0.08333 & 1.002 & 9.4266 & 9.0408 & 1.043 \\
16 & 0.06313 & 0.06250 & 1.010 & 12.9790 & 12.3878 & 1.048 \\
24 & 0.04169 & 0.04167 & 1.007 & 19.7805 & 19.0816 & 1.037 \\
49 & 0.02093 & 0.02041 & 1.025 & 40.3880 & 40.0000 & 1.010 \\
\hline
\end{tabular}

These examples evidently agree with the proposal that (21), (22), and (23) be used for error. estimation. The last columns of Tables VIII and IX (as well as of Table VI) indicate that $\nu_{u}^{*}$ is a little less than the correct $\nu_{u}$, which makes the estimate $s^{2}(\bar{u})$ in (22) slightly conservative (i.e., slightly too large, on the average). 


\section{APPENDIX A}

\section{Computer Generation of Gaussian (Normal) Random Deviates}

Some discussion may be warranted, since the "library" program we started with gave us trouble. A common method for computer calculation of Gaussian random deviates (GRD) is through the use of the relation ${ }^{2}$

$$
y=\frac{\left(\sum_{i=1}^{k} x_{i}\right)-\frac{1}{2} k}{\sqrt{\frac{1}{12} k}},
$$

where the $x_{i}$ are uniformly distributed random numbers (UDRN) over the interval zero to one. With $z=\sum_{i=1}^{k} x_{i}, E(z)=\frac{1}{2} k$, and $\sigma^{2}(z)=\frac{1}{12} k$, then $y$ is the standardized random variable $[z-\varepsilon(z)] / \sigma(z)$, so the mean is $E(y)=0$ and the variance is $\sigma^{2}(y)=1$. Evidently $y$ is also the standardized form of the mean $\bar{x}=\mathrm{z} / \mathrm{k}$, since dividing numerator and denominator by $\dot{k}$ gives $\mathrm{y}=[\overline{\mathrm{x}}-\varepsilon(\overline{\mathrm{x}})] / \sigma(\overline{\mathrm{x}})$, with $\varepsilon(\overline{\mathrm{x}})=\frac{1}{2}$ and $\sigma^{2}(\overline{\mathrm{x}})=1 /(12 \mathrm{k})$.

Although the $\mathrm{y}$-distribution $\mathrm{P}(\mathrm{y})$ is known to approach a true Gaussian distribution (mean zero, unity variance) asymptotically, i.e., as $\mathrm{k}$ approaches infinity, the approximation is very good even for quite small values of $k$.

TABLE A.1. Comparison of Moments of the Distributions of a Gaussian and a Standardized Mean from a Uniform Distribution

\begin{tabular}{cc|cc}
\hline & $\frac{\mu_{\mathrm{r}}(\mathrm{y})}{\mu_{\mathrm{r}} \text { (gauss) }}$ & $\mathrm{r}$ & $\frac{\mu_{\mathrm{r}}(\mathrm{y})}{\mu_{\mathrm{r}} \text { (gauss) }}$ \\
\hline 2 & 1.0000 & 6 & $1-0.0524$ \\
4 & $1-0.0333$ & 8 & $1-0.1843$ \\
\hline
\end{tabular}
$P(y)$ is slightly narrower than the Gaussian for larger y-values, as shown by the fact that the higher moments around the mean (which depend heavily. upon the distribution of large $y$-values) are less than the Gaussian values. Table A.l illus trates this for $k=12$, with $\mu_{r}=\underline{r}$ th moment around the mean. That $\mathrm{P}(\mathrm{y})$ for this case approximates very closely to a Gaussian. is indicated by the fact that only the 8 th moment deviates to significant extent from the Gaussian value. The extent of the deviation in probability values is illustrated in Table A.2, again for $k=12$.

Even were the deviations of $P(y)$ from an exact Gaussian even larger, this would be of no significance in the Monte Carlo calculation, because: 
(1) $\sigma^{2}(y)=1$, so that the true variance of the random deviates is the value used in the calculations.

(2) The expectation of an $s^{2}$-estimate is the variance of the distribution, no matter what the distribution is. Hence, quantities such as in (2), (16), (17), or (25) are unbiased estimates of the corresponding variances, for any distribution.

This would be true only if the $x_{i}$ 's were truly randomly and independently selected from some fixed distribution. If, as discussed below, the $x_{i}$ 's have some correlations whose values change with time, or if their distribution changes with time, there would be no function $P(y)$ which represents a distribution of $y$-values from $(A-1)$.

TABLE A.2. Comparison of Probability Values Calculated for Gaussian and Standardized Uniform Distribution Mean ${ }^{\mathrm{a}}$

\begin{tabular}{|c|c|c|c|c|c|c|c|}
\hline & $\begin{array}{c}\text { Uniform } \\
\text { Distribution }\end{array}$ & Gaussianc & & & $\begin{array}{c}\text { Uniform } \\
\text { Distributionb }\end{array}$ & Gaussianc & \\
\hline $\mathrm{C}$ & A & $\cdots$ & $A-B$ & $\mathrm{C}$ & A & $\mathrm{B}$ & $A-B$ \\
\hline 0.2 & 0.07829 & 0.07296 & -0.00097 & 2.2 & 0.48673 & 0.48610 & 0.00063 \\
\hline 0.4 & 0.15366 & 0.15542 & -0.00176 & 2.4 & 0.49246 & 0.49180 & 0.00066 \\
\hline 0.6 & 0.22352 & 0.22575 & -0.00223 & 2.6 & 0.49593 & 0.49534 & 0.00059 \\
\hline 0.8 & 0.28582 & 0.28814 & -0.00232 & 2.8 & 0.49791 & 0.49744 & 0.00047 \\
\hline 1.0 & 0.33927 & 0.34134 & -0.00247 & 3.0 & 0.49899 & 0.49865 & 0.00031 \\
\hline 1.2 & 0.38336 & 0.38493 & -0.00157 & 3.2 & 0.49954 & 0.49931 & 0.00023 \\
\hline 1.4 & 0.41829 & 0.41924 & -0.00095 & 3.4 & 0.49981 & 0.49966 & 0.00015 \\
\hline 1.6 & 0.44485 & 0.44520 & -0.00035 & $3.6^{\circ}$ & 0.499925 & 0.499841 & 0.000084 \\
\hline 1.8 & 0.46422 & 0.46407 & 0.00015 & 3.8 & 0.499973 & 0.499928 & 0.000045 \\
\hline 2.0 & 0.47772 & 0.47725 & 0.00047 & 4.0 & 0.499991 & 0.499968 & 0.000023 \\
\hline
\end{tabular}

a

$A=\int_{\frac{1}{2}}^{\frac{1}{2}+C \sigma(\bar{x})} T(\bar{x}) d \bar{x}=\int_{\frac{1}{2}-C \sigma(\bar{x})}^{\frac{1}{2}} T(\bar{x}) d \bar{x}=\int_{0}^{C \sigma(y)} P(\dot{y}) d y=\int_{-C \sigma(y)}^{0} P(\dot{y}) d y$,

with $\sigma(\bar{x})=1 /(12 k)$ and the distribution $T(\bar{x})$ is given in Ref. 3 .

$B \quad B=\int_{0}^{C \sigma(w)} Q(w) d w=\int_{-C \sigma(w)}^{0} Q(w) d w$, with $\sigma(w)=1$ and $Q(w)=\frac{1}{\sqrt{2 \pi}} e^{-\frac{1}{2} w^{2}}$.

${ }^{\mathrm{b}}$ Evaluated by direct integration of $\mathrm{T}(\overline{\mathrm{x}})$.

CFrom Ref. 4.

It is common to simplify computation by choosing $\mathrm{k}=12 ; \mathrm{Eq} .(\mathrm{A}-1)$ then becomes

$$
y=\left(\sum_{i=1}^{12} x_{i}\right)-6.0
$$


This is a particularly suitable form for electronic computation, since it involves only the fast operations of addition and subtraction, and eliminates the relatively slow operations of division and square root.

Sequences of uniformly distributed random numbers were not available in the quantities needed in this calculation, so sequences of pseudorandom numbers (PRN) were computer generated. Such sequences need not be the complete equivalent of (UDRN), but they should be close to uniformly distributed and they should not exhibit troublesome correlations..

The simplest test for the adequacy of an algorithm for generating $(P R N)$ is a chi-square test for the uniformity of the distribution. The quantities of (PRN) found in 100 or 1000 equal bins from 0 to 1 are compared to the expected values. Surprisingly enough, some of the algorithms in common use fail this simple test under some conditions.

Correlation effects are sometimes more subtle, and may not show up in the chi-square test, which only tests for uniformity of distribution. Since $(A-2)$ sums twelve sequentially neighboring $x_{i}$ 's from the (PRN) generator, pockets of close-order correlation can distort the $y$-distribution so that it changes along the sequence.

One of the algorithms tested passed the chi-square test, but yielded results which deviated excessively from expected values; that is, it gave large values for the ratios $\Delta \mathrm{s}^{2} / \sqrt{\mathrm{V}_{\mathrm{S}}}$ ( see Table V.) and of $\Delta \overline{\mathrm{S}_{\mathrm{U}}} / \sqrt{\mathrm{V}_{\mathrm{S}}}$ (see Table VI). Indeed; we had accepted on faith the adequacy of the library (PRN)-generator and were first alerted to its inadequacy by noting that the ratios in Tables $\mathrm{V}$ and. VI were much too large.

Three algorithms for computer generation of (PRN) were investigated. In the first, one chooses, for example, a ten-digit number at random, squares this, then selects the central ten digits of the result as the new random number; this is continued to make the desired (PRN) sequence. While this method may be suitable for generating a few thousand (PRN), it is not useful where $10^{5}$ or more numbers are required.

One difficulty is that if the (PRN) sequence is approximately random at the beginning of the sequence, then, on the average, the five terminal (i.e., low order) digits will all be zero about one time in $10^{5}$. In subsequent squaring, the final five digits of the central ten remain as zeroes. Further, of the five initial digits, the fifth (last) one becomes constant in sequential squaring, since higher powers of any integer eventually terminate in either $0,1,5$, or 6 and then repeat indefinitely. After this, only the first four digits vary and the sequence begins to repeat itself with a relatively short period. Failure of the test for uniformity (chi-square test) was the first indicator of trouble; an examination of the output list showed the evident periodicity. 
In a more sophisticated technique, ${ }^{5}$ one starts with an arbitrarily chosen integer $X_{i}$, forms $\left[X_{i}+X_{i}\right]$, and then takes for the residue modulo a suitable prime number $P$. The residue becomes the new random number $\mathrm{X}_{\mathrm{i}+1}$, and the process is repeated. It can be shown that if the prime number is of the form $(8 n+3)$ or $(8 n+5)$, this procedure selects every integer between 1 and $\mathrm{P}-1$ exactly once before repeating the cycle. If $P$ is chosen very large and very near a power of ten (for example, $999,999,893$ ), the scheme generates without repetition a large number of "uniformly distributed" integers $\mathrm{X}_{\mathrm{i}}$ (nearly $10^{9}$ in the example) that can be converted to the range $0 \leqq x_{i} \leqq 1$ by merely shifting the decimal point. This method also has the advantage of requiring only addition, subtraction, and movement of the decimal point, all relatively fastoperations.

While this technique does indeed generate (PRN) that satisfy simple tests for randomness and uniformity of distribution, the sequences turned out to be unsuitable for generation of (GRD) with (A-2). The chi-square test indicated uniformity at the beginning of a long sequence, but showed deviations in later parts of the sequence. The difficulty is that correlation between nearby members of the sequences can and does occur. For example, doubling a number that is slightly greater than $\frac{1}{2} \mathrm{P}$ gives a resultant close to zero. Subsequent iterations give integers that remain close to zero. Similarly, doubling a number just under $\frac{1}{2} P$ yields a sequence of relatively large numbers, all just under $P$. The (GRD) calculated from such sequences have large negative and positive means, respectively, and small variances.

Further, if one of the (PRN) is very nearly $P / 3$, then the sequence approximate $\mathrm{P} / 3,2 \mathrm{P} / 3, \mathrm{P} / 3,2 \mathrm{P} / 3, \mathrm{P} / 3,2 \mathrm{P} / 3$, etc. (GRD) obtained by summing these numbers have the correct mean, but the variance tends to be much too low. Similar almost-repeating sequences occur if one of the random numbers approximates $P / 7, P / 15$, or any number of the form $\mathrm{P} /\left(2^{\mathrm{n}}-1\right)$.

The most common algorithm currently used to produce (PRN) over the range $0 \leqq \mathrm{x} \leqq 1$ is the "multiplicative congruential generator, "i.e.,

$$
\mathbf{x}_{\mathbf{i}+1}=\alpha \mathrm{x}_{\mathbf{i}}+\beta \quad \text { Modulo } \mathrm{M} \text {, }
$$

where $M$ is usually a power of two for a binary machine and a power of ten for a decimal machine, and $\alpha$ and $\beta$ are integers. Several generators of this type were tested, varying the initial $x_{i}$ and $\alpha$ independently. While some did indeed produce numbers satisfying a simple chi-square test for uniformity, the (GRD) derived from these sequences did not have unity variance, though they were closer to it than those from the previous method described. Apparently, there was still some close order correlation, and this tendency has been noted in the literature..$^{6,7}$ 
The technique finally used.was an elaboration of a method described by Marsaglia and MacLaren, ${ }^{6}$ in which the sequences were "scrambled" to destroy close-order correlations. Three generators of the congruential multiplicative type were employed, plus a table of 100 five-digit random numbers. The method was as follows:

(1) When a random number was required, generator No. l would produce a four-digit number.

(2) The first two digits served as matrix coordinates to select one of the 100 table entries, and this was the output number.

(3) The next two digits determined whether generator No. 2 or generator No. 3 would be employed to produce a five-digit replacement for the table entry extracted.

Steps 1, 2, and 3 were used every time a (PRN) was requested.

Thus, the output sequences of two generators were both scrambled and intermixed. A machine-language subroutine was written that would initiate this process 12 times and subtract 6 from the sum whenever the main program called for a (GRD). In addition, the deviates that were thus obtained were automatically tested by the main program through computation of the mean and variance of the (GRD) used; these were periodically printed out with the main results. In the course of the Monte Carlo calculations. more than $10^{6}$ Gaussian deviates were generated and tested, and no departures from expected behavior were observed. The Gaussian deviates themselves had approximately zero mean and unit variance in groups and, in toto, deviating by only the statistically expected amounts. The last columns of Tables V and VI indicate good agreement between the Monte Carlo results and expected values for the straight line case. This is an overall test for the sequence of $10^{6}$ Gaussian deviates used [hence, . $\sim 10^{7}$ (PRN)]. Similar checks made for subsections of the data showed comparable agreements. 


\section{B IBLOGRAPHY}

1. A. H. Jaffey and J. Lerner, Measurement of Prompt Neutron Fission Yield ( $\left.\bar{v}_{p}\right)$ in Thermal-neutron Fission of $232 \mathrm{U}, 238 \mathrm{Pu}, 241 \mathrm{Pu}, 241 \mathrm{Am}, 242 \mathrm{~m} \mathrm{Am}, 243 \mathrm{Cm}$, $245 \mathrm{Cm}$, and in Spontaneous Fission of $244 \mathrm{Cm}$, to be published.

2. R. W. Hammings, Numerical Methods for Scientists and Engineers, McGraw-Hill Book Co., Inc., New York (1962), pp. 34 and 389.

3. M. G. Kendall and A. Stuart, The Advanced Theory of Statistics. Vol. I. Distribution Theory, Hafner, New York (1958), Ch. 11.

4. E. S. Pearson and H. O. Hartley, Biometrika Tables for Statisticians, Vol. I, Cambridge University Press, Cambridge (1962).

5. F. J. Gruenberger and D. D. McCracken, Introduction to Electronic Computers, John Wiley \& Sons, Inc., New York (1963).

6. M. D. MacLaren and G. Marsaglia, Uniform Random Number Generators, J. ACM 12, 83-89 (Jan 1965).

7. G. Marsaglia, Random Numbers Fall Mainly in the Planes, Proc. Nat1. Acad. Sci. U.S., 60, 5 (Sept 1968). 